\title{
Insights into the foraging behaviour of an understudied orca population
}

\author{
Mel Cosentino ${ }^{1, *}$ and Nacho Oria ${ }^{2}$ \\ ${ }^{1}$ Wild Earth Foundation, Av de las Ballenas 9500, U9121XAQ, Puerto Pirámides, Peninsula Valdes, Chubut, Argentina \\ ${ }^{2}$ Sedna Project, Calle Remences 6, 17005 Girona, Spain \\ *Corresponding author: orcinus.orca.1758@gmail.com
}

Orcas, Orcinus orca, are the most widely distributed aquatic mammals and are found in all of the world's oceans (Forney and Wade, 2007). Their diet includes over 140 species of fish, cephalopods, seabirds, turtles, and aquatic mammals, including more than 20 cetacean species, from small porpoises to great whales (e.g. Jefferson et al., 1991). However, different populations, even sympatric ones, are specialized in feeding on certain prey items. For example, on the west coast of the US and Canada, there is a "transient" type feeding almost exclusively on aquatic mammals, a "resident" type feeding on fish, and a third "offshore" sympatric ecotype found off California, which specialises in feeding on sharks (Ford et al., 1998; Dahlheim et al., 2008). These populations not only differ in their diet, but also in their morphological traits, acoustic behaviour, and social structure (Bigg et al., 1990, Ford et al., 1998), and are known as ecotypes.

Orcas off Baja California (Mexico) have not been studied systematically and knowledge about them comes mainly from opportunistic observations or stranded individuals (Guerrero-Ruiz et al., 1998; 2006). They seem to be sporadic visitors, with fewer than 200 sightings over the past three decades; however, they are seen almost every year, any month of the year. Moreover, some individuals have been resighted within and between years, up to 14 years later, and at least four communities were identified and resighted in the Gulf of California in the 1990s, including a group that was regularly seen off Los Angeles (United States) (Guerrero-Ruiz et al., 1998). Little is known about their whereabouts and recent data show that at least some individuals engage in long-distance movements, given the observation of a group previously sighted off California and one animal was seen moving between Mexico and Peru (Guerrero-Ruiz et al., 2005).

Their diet is also unknown (Guerrero-Ruiz et al., 1998), although

\section{ARTICLE INFO}

Manuscript type: Note

\section{Article History}

Received: 23 June 2020

Received in revised form: 12 June 2021

Accepted: 28 June 2021

Available online: 23 August 2021

Responsible Editor: Miriam Marmontel

Citation:

Cosentiño, M. and Oria, N. (2021) Insights into the foraging behaviour of an understudied orca population. Latin American Journal of Aquatic Mammals 16(1): 51-53.

https://doi.org/10.5597/lajam00272 opportunistic observations (Christopher Swann, Photographer, pers. comm., 17 March 2019) suggest they prey on marine mammals and other prey items, such as sharks, as some stranded animals had almost fully worn teeth (Guerrero-Ruiz et al., 2006).

Orcas are just one of the 38 cetacean species that visit Baja California (e.g. Arellano-Peralta and Medrano-González, 2015) and are the target of the whale watching industry if the opportunity arises. Because whale-watching vessels spend most of the day at sea and cover large areas (Amerson and Parsons, 2018), the activity provides a platform to conduct research on cetaceans, especially species rarely seen in the area, such as orcas. Here, we report and describe a foraging event involving orcas chasing and likely feeding on a short-beaked common dolphin, Delphinus delphis, off Baja California.

The event took place off the town of Los Cabos, at $22^{\circ} 54^{\prime} 57.6^{\prime \prime} \mathrm{N}$ and $109^{\circ} 48^{\prime} 21.6^{\prime \prime} \mathrm{W}$ (Fig. 1), in the Gulf of California, on 13 February 2018. The observation was made by NO from Gratitud, a 14-m long fiberglass vessel that belongs to Whale Watch Cabo SA. Gratitud was the only vessel in the area during the entire event. Photographs were taken using a DSLR Nikon D5300 camera equipped with a Nikon 70-300 mm f4-5.6 G AF lens, and videos were taken with an iPhone SE ( $1^{\text {st }}$ generation).

At 12:38 pm, a group of about 200 short-beaked common dolphins was seen at approximately $1.8 \mathrm{~km}$ off the coast of Los Cabos (22 $\left.53^{\prime} 20.4^{\prime \prime} \mathrm{N} 109^{\circ} 50^{\prime} 31.2^{\prime \prime} \mathrm{W}\right)$, moving in the northwest direction. The dolphins were traveling, and the group consisted of adults, juveniles, and calves. At 12:40 pm, a group of orcas was seen approximately $200 \mathrm{~m}$ in front of the whale watching vessel $\left(22^{\circ} 53^{\prime} 56.4^{\prime \prime} \mathrm{N} 109^{\circ} 49^{\prime} 12.0^{\prime \prime} \mathrm{W}\right)$, travelling southwest, towards the dolphins. Based on the shape of the dorsal fin and the body length, the group seemed to be comprised by four adult females (some could have been immature males) and a juvenile of unknown sex. At $12: 43 \mathrm{pm}$, the orcas reached the dolphin group $\left(22^{\circ} 53^{\prime} 06.0^{\prime \prime} \mathrm{N}\right.$ $\left.109^{\circ} 49^{\prime} 44.4^{\prime \prime} \mathrm{W}\right)$, who dispersed rapidly, with animals breaching out of the water while moving in all directions, and gathering in smaller groups, a typical flight response for small cetaceans (e.g. Coscarella et al., 2015; Fig. 2). At 12:44 pm, the orcas were moving close to each other and surfacing at the same time, but they broke formation when a dolphin became isolated from the rest of the group, near the orcas (Fig. S1). At this point, the orcas became more active and one of the (presumably) adult females breached completely out of the water, at an approximate height of $3 \mathrm{~m}$, while expelling water from the mouth, hereafter "jetting". The orca curved the body creating an arch in the air and the water coming out of the mouth seemed to be directed towards the dolphin, which seemingly changed directions (Fig. 3). 
During this first minute $(12: 44 \mathrm{pm})$, the female came out to breathe, breached once without jetting and once more (it is not clear if jetting occurred in this breaching), after which a second orca joined the chase (12:45 pm). Subsequently, the first individual from before breached again without jetting (Fig. S2). At 12:46 $\mathrm{pm}$, another orca, possibly the juvenile (based on body size) also breached (Fig. S3), while the rest of the pod remained underwater. Although there were three orcas engaged in the chase at this point, only two surfaced at a time. Over the next few minutes, the dolphin made fast turns, but as the orcas continued with the chase, its movements became slower (Fig. 4), until (12:49 pm) one orca breached in the vicinity of the dolphin (Fig. S4). The dolphin was last seen (12:50 pm) closely ahead of two orcas (Fig. S5).

The chase lasted about seven minutes and finished at $22^{\circ} 54^{\prime} 57.6^{\prime \prime} \mathrm{N} 109^{\circ} 48^{\prime} 21.6^{\prime \prime} \mathrm{W}$ (Fig. 1). At this point, the three orcas involved became less active, first arching the body when submerging and then, for the first time since before the chase, they surfaced together. For the next 15 minutes, the orcas were swimming slowly and appeared on the surface almost
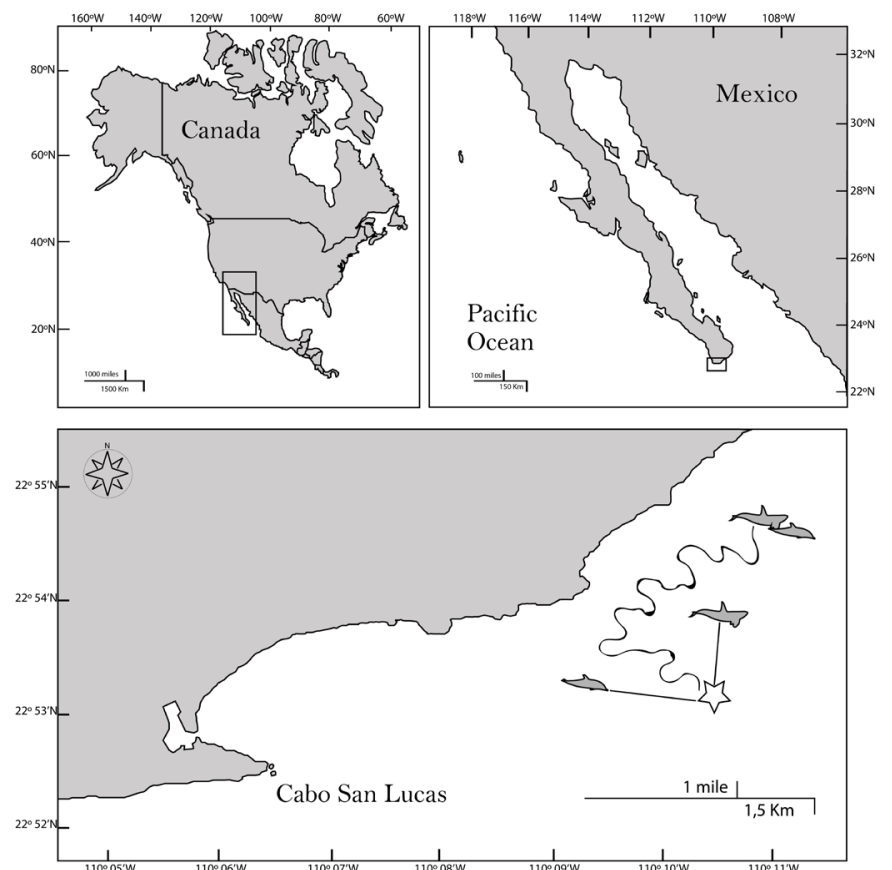

Figure 1. Map of the whale-watching and study area in Southern Baja California, Mexico. Top left panel: location of the study area in the continent. Top right panel: zoomed in study area. Lower panel: schematic of the event observed. The star signals the meeting point of the orcas, Orcinus orca, with the group of short-beaked common dolphins, Delphinus delphis. The line represents the general direction of the chase, which ends at the figure of the orca and dolphin.

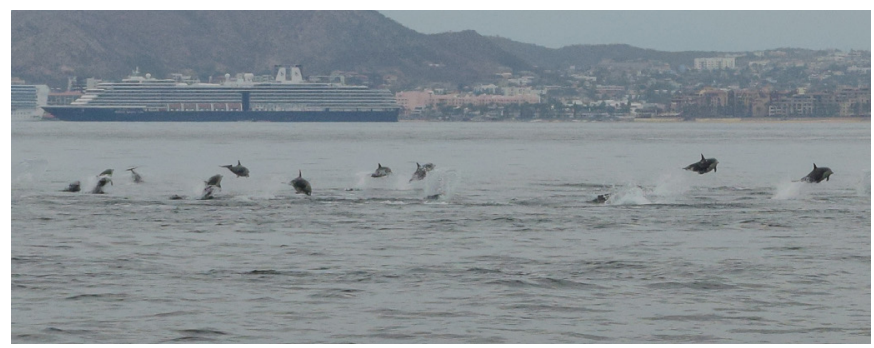

Figure 2. Group of short-beaked common dolphins, Delphinus delphis, showing a flight response to the presence of orcas, Orcinus orca, off Cabo San Lucas, Baja California, Mexico. simultaneously, although not always heading in the same direction, surfacing consistently approximately every eight seconds. At 13:05, the other two orcas rejoined the group, which stayed some minutes milling in the area, spending longer periods underwater. Soon after, the orcas got closer to each other and began travelling slowly towards the open sea, in a north-eastern direction. The behaviour of the orcas after the chase ended suggested the dolphin could have been killed and consumed by the three individuals involved in the chase. However, confirmation was not possible through direct (e.g. flesh) or indirect observation (e.g. presence of birds).

Orcas in these waters had been observed feeding on cetaceans before. In 2013, a group of 5-7 orcas was seen in the same area chasing and likely feeding on a bottlenose dolphin Tursiops truncatus (Christopher Swann, Photographer, pers. comm., 17 March 20). Similar to what was observed in the event reported here, one individual did most of the chasing, repeatedly breaching, exposing the entire body out of the water. Additionally, there were no adult males during the event and the juveniles actively engaged in the chase. Photographs from the two events were compared and no matches between individuals were found; however, because not all animals could be identified, it was not possible to confirm that none of the animals were involved in both events. In May $2021^{1}$, a group of at least seven orcas off Baja California made the international news when they were filmed from whale watching vessels chasing a bottlenose dolphin. The event also involved a (presumably) adult female breaching entirely out of the water, in this case ramming the dolphin. No adult males were observed.

The similarities between these events provide insights into the ecology and foraging behaviour of orcas off Baja California. In all cases, the group size was small, which in this species is usually an indication they specialise in feeding on aquatic mammals. For example, transient orcas off the North Pacific feed almost exclusively on aquatic mammals and travel in groups of 1 to 15 individuals, although the most common group size is 3 (Baird and Dill, 1995). On the other hand, resident orcas that feed almost exclusively on fish live and travel in larger groups (Bigg et al., 1990). Similar group sizes were observed for orcas off Scotland and Iceland (Beck et al., 2012). Orcas in the Gulf of California are seen in groups of between one and 30 individuals, with a mean of 5.5 ( $S D= \pm 0.8$ ), and most groups consisting of fewer than seven animals (Guerrero-Ruiz et al., 1998, 2006).

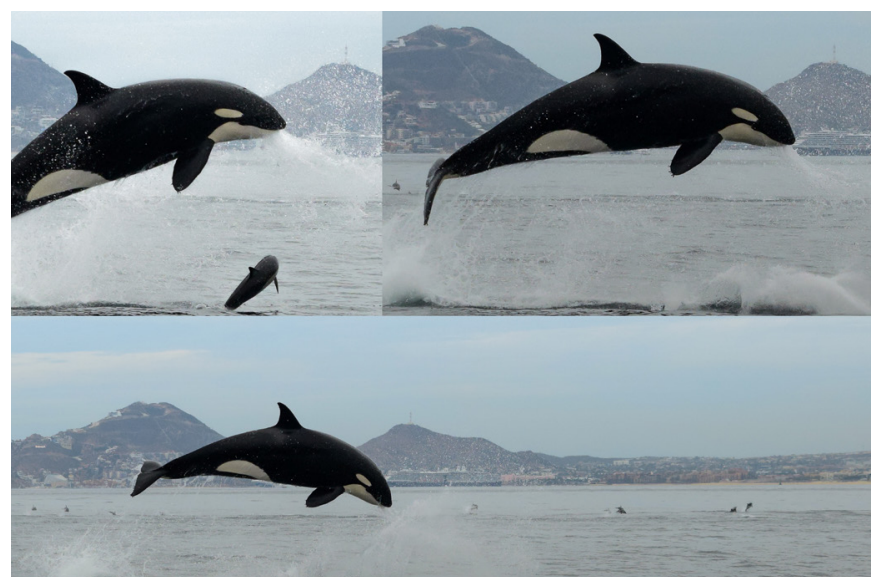

Figure 3. Sequence of images (from upper left to bottom) showing an orca, Orcinus orca, spewing water from its mouth, behavior seen when chasing a short-beaked common dolphin, Delphinus delphis. 


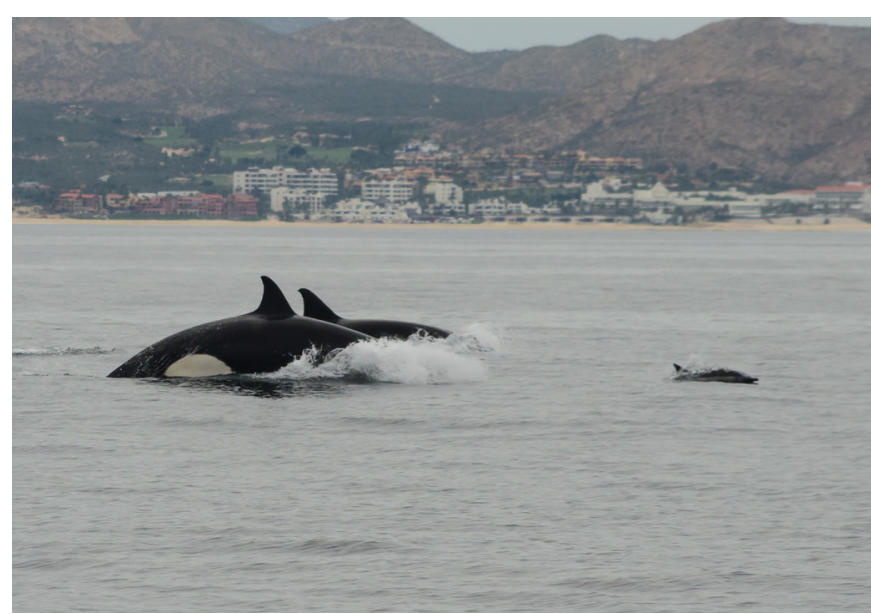

Figure 4. Two orcas, Orcinus orca, chasing a short-beaked common dolphin, Delphinus delphis, that became isolated from its group off Cabo San Lucas, Baja California, Mexico.

The cooperative aspect of these observations is consistent with what has been seen in other populations. For example, along the Antarctic Peninsula, ecotype B orcas hunt seals that are resting on floating ice, especially Weddell seals, Leptonychotes weddellii, by swimming close to each other at high speeds, generating waves as they pass under the ice. The wave washes the seal off into the water where the orcas, including juveniles and calves, work together to capture the seal, which is shared between group members (Pitman and Durban, 2012).

The events discussed here are the first descriptions in the literature of potential predatory events of orcas off Baja California. While whether jetting is used for foraging purposes remains unclear, these events suggest breaching is. These observations provide insights into the ecology of this understudied orca population and is another example of the value of whale watching vessels as research platforms to gain behavioural and ecological knowledge of understudied cetacean populations, especially in areas with limited access to resources.

\section{Acknowledgements}

We would like to thank the company Whale Watch Cabo S.A. for allowing the use of the vessel as an opportunistic research platform and M. Serra for providing the footage of the event. We would like to thank C. Swann for providing photographs for matching purposes.

\section{References}

Amerson, A. and Parsons, E.C.M. (2018) Evaluating the sustainability of the gray-whale-watching industry along the Pacific coast of North America. Journal of Sustainable Touism 9582: 1-19. https://doi.org/10.1080/09669582.2018.1449848

Arellano-Peralta, V.A. and Medrano-González, L. (2015) Ecology, conservation and human history of marine mammals in the Gulf of California and Pacific coast of Baja California, Mexico. Ocean Coastal Management 104: 90-105.

https://doi.org/10.1016/j.ocecoaman.2014.12.004
Baird, R.W. and Dill, L.M. (1995) Occurrence and behaviour of transient killer whales: seasonal and pod-specific variability, foraging behaviour, and prey handling. Canadian Journal of Zoology 73(7)? 1300-1311 https://doi.org/10.1139/z95-154

Beck, S., Kuningas, S., Esteban, R. and Foote, A.D. (2012) The influence of ecology on sociality in the killer whale (Orcinus orca). Behavioral Ecology 23: 246-253.

https://doi.org/10.1093/beheco/arr151

Bigg, M., Olesiuk, P.F., Ellis, G.M., Ford, J.K.B. and Balcomb, K.C. (1990) Social organizations and genealogy of resident killer whales (Orcinus orca) in the coastal waters of British Columbia and Washington State. Pages 383-405 in Hammond, P.S., Mizrock, S.A. and Donovan, G.P. (Eds) Reports of the International Whaling Commission (Special Issue 12). https://doi.org/10.1098/rsbl.2010.0638

Coscarella, M.A., Bellazzi, G., Gaffet, M.L., Berzano, M. and Degrati, M. (2015) Technique used by killer whales (Orcinus orca) when hunting for dolphins in Patagonia, Argentina. Aquatic Mammals 41: 1-6. https://doi.org/10.1578/AM.41.2.2015

Dahlheim, M.E., Schulman-Janiger, A., Black, N.A., Ternullo, R., Ellifrit, D.K.D. and Balcomb, K.C. (2008) Eastern temperate North Pacific offshore killer whales (Orcinus orca): Occurrence, movements, and insights into feeding ecology. Marine Mammal Science 24: 719-729.

https://doi.org/10.1111/j.1748-7692.2008.00206.X

Ford, J.K.B., Ellis, G.M., Barrett-Lennard, L.G., Morton, A.B. and Balcomb, K.C. (1998) Dietary specialization in two sympatric populations of killer whales (Orcinus orca) in coastal British Columbia and adjacent waters. Canadian Journal of Zoology 76: 1456-1471. https://doi.org/10.1103/PhysRevLett.119.202002

Forney, K.A. and Wade, P.R. (2007) Worldwide distribution and abundance of killer whales. Pages 145-162 in Estes, J.A., DeMaster, D.P., Doak, D.F., Williams, T.M., Brownell, R.L. (Eds) Whales, Whaling, Ocean Ecosystems. University of California Press.

https://doi.org/10.1525/california/9780520248847.003.0012

Guerrero-Ruiz, M., Gendron, D. and Urbán R., J. (1998) Distribution, movements and communities of killer whales (Orcinus orca) in the Gulf of California, Mexico. Reports of the International Whaling Commission 48: 537-543.

Guerrero-Ruiz, M., García-Godos, I. and Urbán R., J. (2005) Photographic match of a killer whale (Orcinus orca) between Peruvian and Mexican waters. Aquatic Mammals 31: 438-441. https://doi.org/10.1578/AM.31.4.2005.438

Guerrero-Ruiz, M., Pérez-Cortés M., H., Salinas Z., M. and Urbán R., J. (2006). First mass stranding of killer whales (Orcinus orca) in the Gulf of California, Mexico. Aquatic Mammals 32: 265-272. https://doi.org/10.1578/AM.32.3.2006.265

Jefferson, T.A., Stacey, P.J. and Baird, R.W. (1991) A review of killer whale interactions with other marine mammals: predation to co-existence. Mammal Review 21: 151-180. https://doi.org/10.1111/j.1365-2907.1991.tb00291.x

Pitman, R.L. and Durban, J.W. (2012) Cooperative hunting behavior, prey selectivity and prey handling by pack ice killer whales (Orcinus orca), type B, in Antarctic Peninsula waters. Marine Mammal Science 28: 16-36. https://doi.org/10.1111/j.1748-7692.2010.00453.x 